\title{
Equivalent Substitution Based Method for Calculation of Best Installed Capacity of Pumped Storage Power Station
}

\author{
Jinming Li, Tao Yu, Huaizhi Wang \\ College of Electric Power, South China University of Technology, Guangzhou, Guangdong Province, China \\ Email: li407516762@163.com
}

Received 2013

\begin{abstract}
This paper proposes a novel method to calculate the best installed capacity of pumped storage power station. First, we choose the day with maximum load as the typical day for every month and simulate the system running in two cases of whether the pumped storage power station is put into operation. The difference of the total coal consumption between the two cases is the peak load shifting benefit. Furthermore, we build load model and power generation model to calculate the benefit of emergency use and frequency modulation, which are the major projects of dynamic benefits. At last, on the premise of ensuring the system requirements, the developed method employs the maximum benefit of the unit capacity as the objective function to get the best installed capacity of pumped storage power station by simulations. Tests on a provincial power grid have shown that the developed method which combines of load characteristics, electric structure and other factors can get the best installed capacity of pumped storage power station easily and has a certain guiding significance for the planning and construction of the pumped storage power station.
\end{abstract}

Keywords: Static Benefits; Dynamic Benefits; Pumped Storage Power Station; Best Installed Capacity

\section{Introduction}

With the sustainable and rapid development of china economy, the electric power demand is also increasing rapidly, which make the fluctuation of load and peak valley load increasing year by year. Thermal power plants are the major producer of electricity in China, but the output regulating scope of most thermal power plants is less than $50 \%$ and cannot meet the demand of the load variation. The pumped storage power station is built to solve this problem. When the power system is in low load condition, the pumped storage units begin pumping water from the reservoir in downriver to the reservoir in upstream and release the water when the load begin to increase, in this time ,the pumped storage units work in the condition of generating[1,2]. In this way, the pumped storage units can store energy. The pumped storage power station is not affected by factors such as fuel, flood etc., and the regulating scope of pumped storage units is the double of its rating $[3,4]$. At this point, pumped storage units show great superiority comparing with other normal power supplies. Therefore, in the region with greatly fluctuating load but lacking of shift peak load capacity, building pumped storage power station is the best measure to mitigate the difficulty of peak regulation and lack of peak power.

In addition, pumped storage power station has good dynamic function, such as frequency modulation, phase modulation, spare, black start etc., which make it be a very effective tool and mean to ensure the security, economy and stability of power grid.

It involves many factors to determine the reasonable proportion of pumped storage power station in the power system, including the current situation of energy development and utilization, the electric structure, the distribution of power station, the load characteristic, the pumping power that power system can provide, the development condition and the investment and operation cost of all kinds of power plant. This paper employs the maximum benefit of the unit capacity as the objective function to get the best installed capacity of pumped storage power station by simulations [5]. Tests on a provincial power grid have shown the effectiveness of the method.

\section{Static Benefits}

The static benefits of pumped storage power station contain two parts, the one is capacity benefit and the other is shift peak and valley benefits. Pumped storage power station can undertake the work of system working capacity and spare capacity effectively, which can reduce the installed capacity of thermal power station and save system investment and operation cost. The resulting economic benefits are called capacity benefits. After the pumped storage power station is put into operation, the system fuel consumption will increase due to the pump- 
ing power of the pumped storage units. On the other hand, because the pumped storage units can replace thermal power unit to be the variable load plant and improve the operating conditions of thermal power unit. In this way, it can reduce the auxiliary power rate and the coal consumption rate of the thermal power unit, the difference value between the two cases is the pumped storage power station's shift peak and valley benefits. The calculation of capacity benefit calculation is relatively simple, but calculating shift peak and valley benefits is a complicated problem which involves many factors.

In this paper, we choose the day with maximum load as the typical day for every month and simulate the system running in two cases of whether the pumped storage power station is put into operation. The forecast of pumped storage power station 24 point output curve in the typical day bases on the data of historical average, and in consideration of the development of installed capacity and load level, we revise the curve proportionally. The 24 point output curve of power from other areas depends on the fixed power energy of the agreement. Specific steps to calculate the Static benefits are shown as follows:

1) Determine the output curve of the other units in the area except pumped storage unit. With the considering of load and emergency reserves, deduct pumped storage power station output and power from other areas from the load curve in the typical day (when the pumped storage power station is on pumping state, its output is a negative value).

2) Sort the units in the power grid. According to the principle of energy-saving power generation dispatching, clean energy unit such as hydropower unit, nuclear reactors are arranged to put into operation first, and how to decide the priorities of thermal power units depend on the unit coal consumption rate.

3) Unit Commitment (UC). The priority listing method is used to solve the UC problem. The method initially arranges the generating units based on lowest operational cost characteristics. The predetermined order is then used for UC such that the system load is satisfied [6,7].

4) Calculate shift peak and valley benefits of pumped storage power station. Add the coal consumption of all units in two cases respectively to get the total coal consumption of the system, then we can obtain the shift peak and valley benefits in the typical day by calculating the difference between the two cases. So it is easy to figure up the shift peak and valley benefits for month and year with monthly unbalanced coefficient and seasonal unbalanced coefficient.

\section{Dynamic Benefits}

Dynamic benefits of pumped storage unit include several aspects, and in the simulation of system operation, they are related to each other. At present, quantitative evaluation algorithms for dynamic benefits usually adopt partial summation model method; its main idea is dividing pumped storage power station capacity into several parts according to the function it undertakes. Then put forward quantitative calculation formula for every part respectively, and calculate the dynamic benefit, the total dynamic benefit of pumped storage power station is the sum of all parts [8].

This paper adopts equivalent replacement method that is widely used in the engineering economics. The first step is calculating the basic program, namely studying the system reliability index and annual cost when the studied station provides dynamic benefit service; The second step consider alternative program, namely calculating the annual cost that is needed to keep the reliability index being same with the basic program when the studied station doesn't provide dynamic benefit service. Comparing with the basic program, the excess part of the annual cost in alternative program is the benefit annual value. This paper focuses on two important items in dynamic benefit: emergency reserves benefit and frequency modulation benefit.

\subsection{Emergency Reserves Benefit}

Starting with the overall system, this paper builds a pumped storage power station accident emergency reserves benefit evaluation model to analysis emergency reserves benefit of pumped storage unit by dynamic simulating of system accident pattern analysis and accident reflection of all kinds of units after in the process of system accident. The emergency reserves benefit evaluation model includes two child models, the one is load model and the other is the power generation model.

Load model. The load model is based on historical load data of power system and the development of social economic characteristics in the future. The load mode consists of three parts: the annual peak load, the annual load curve, the typical daily load curve. The load on the ith moment in the typical day can be calculated as follow:

$$
L_{m t}=L_{\text {max }} \times L_{\mathrm{m}} \times L_{h m t}
$$

where $L_{\max }$ is the annual peak load, $L_{\mathrm{m}}$ and $L_{h m t}$ are the annual load curve (seasonal unbalanced coefficient) and the typical daily load curve, respectively.

Power generation model. Power generation model includes the analysis of system accident pattern and unit response capability model. For simplicity, we count the amount of power failure which need the pumped storage unit response quickly and employ a quadratic fitting method to evaluate the emergency capacity and accident probability over the years. In addition, we assume that load regulation speed of thermal power plants and gaspowered plants are $2 \%$ and $7 \%$ of its rated capacity per 
minute, respectively. Then remove the capacity of full load units from total unit-operating capacity of system and the remaining capacity is the response capacity in the system.

This paper adopt the lacking electricity caused by accident in the year as the reliability index and the flowchart of the method for emergency reserves benefit evaluation is depicted in Figure 1, where $\xi$ and $\xi_{0}$ are reliable index of alternative program and basic program.

\subsection{Frequency Modulation Benefit}

Frequency modulation benefit consists of load reserve benefit and load tracking benefit. According to the research achievement of Prof. A. Ferreira from Electrical Power Research Institute of America, load reserve benefit and load tracking benefit are approximately the same, so this paper only calculate load reserve benefit and Frequency modulation benefit is double of load reserve benefit.

The basic evaluation process of Frequency modulation benefit is similar to that of emergency reserves benefit, the only one difference between them is the load model and power generation model they adopt. Load reserve capacity adjustment of Pumped storage power station is usually due to the imbalance of system instant power caused by unscheduled increasing load and random fluctuations of load. Hence, it is necessary to do a detailed simulation analysis of random fluctuations of load when evaluate the load reserve benefit.

The load model in the evaluation of load reserve benefit is a 24-point typical daily load curve. On that basis, then add short-term unscheduled increasing load and random fluctuations of load into the model. Take the China Southern Grid as an example, the load fluctuate about 150MW when the frequency fluctuate $0.03 \mathrm{~Hz}$. For simplicity, we assume that the typical daily load fluctuation meet the standard normal distribution, so the probability of load fluctuation within 150MW can be calculated as $\phi(2)=0.9772$. Probability of load fluctuation amplitude is shown in Figure 2.

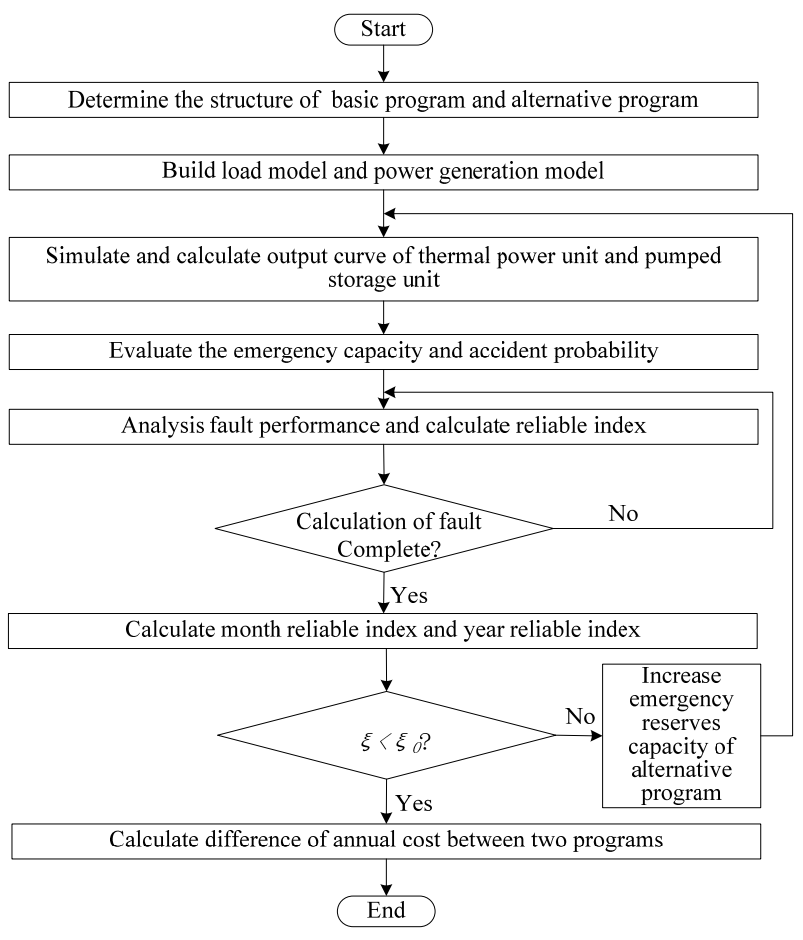

Figure 1. Flowchart of emergency reserves benefit evaluation.

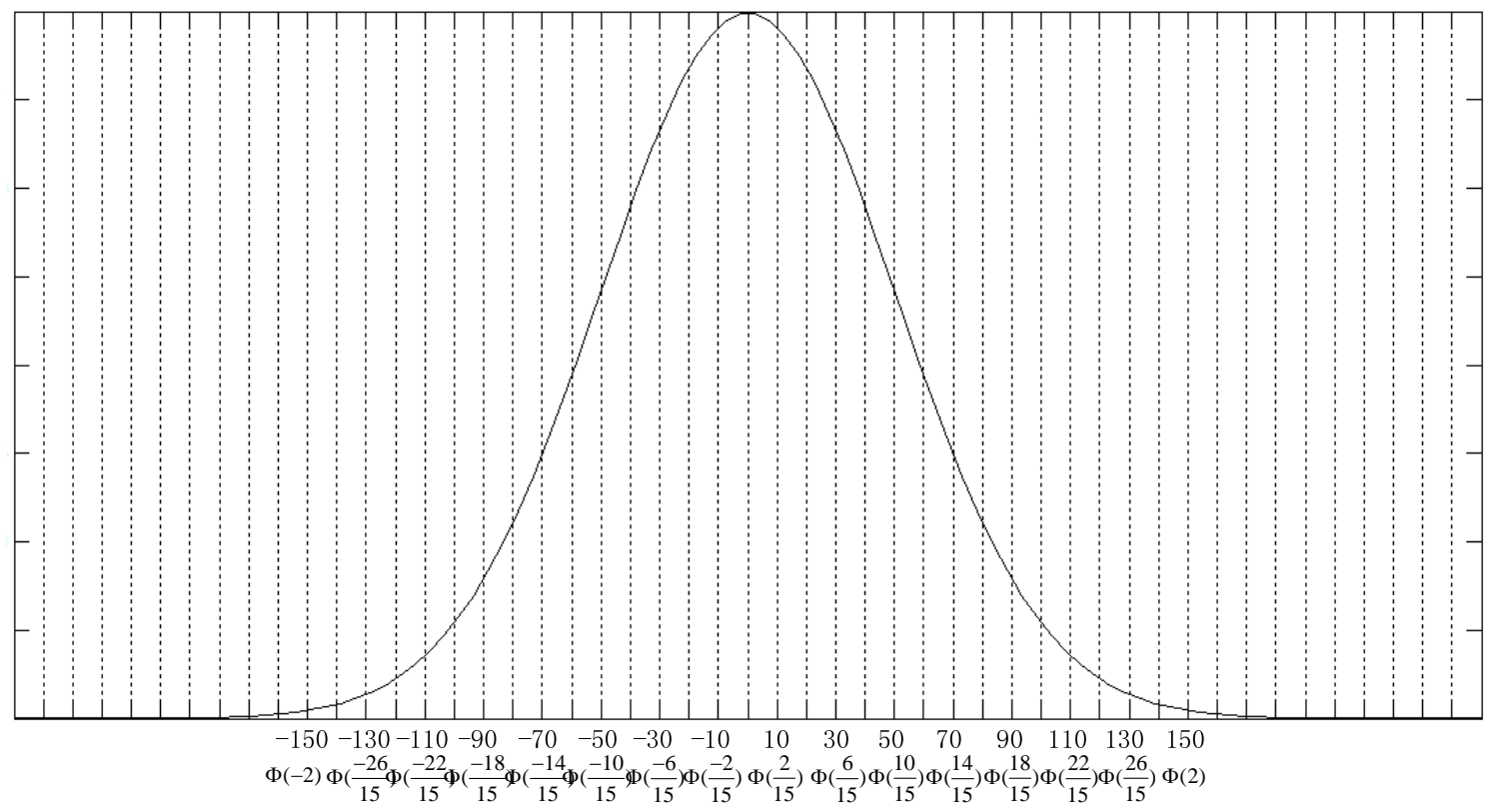

Figure 2. Flowchart of Probability of load fluctuation amplitude. 
On the promise that pumped storage power station have enough capacity to undertake the task of shift peak and valley and emergency reserve, pumped storage units make use of spare capacity and the remaining power for emergency reserve to provide load reserve to system. During low load period, pumped storage units work as a water pump and it will increase the load of system. In this state, it can't be frequency modulation unit and frequency modulation is undertaken squarely by other kinds of units, these would often be thermal power unit. Therefore, the evaluation of load reserve benefit should be divided into rest time and power generation time.

The flowchart of the method for frequency modulation benefit evaluation is depicted in Figure 3, where $\xi$ and $\xi_{0}$ are reliable index of alternative program and basic program.

\section{Example Analysis}

Increase the installed capacity of pumped storage power station according to the unit capacity of pumped storage unit in studied area in the case that load characteristic is known. Then evaluate the total benefit of every scheme, respectively. The capacity that correspond maximum benefit of unit capacity would be the best installed capacity of pumped storage power station. For simplified calculation, we assume that pumped storage units make full use of their capacity. Thus, in the premise of satisfying the requirement of dynamic task, including emergency reserve, load reserve, load tracking etc., all of the

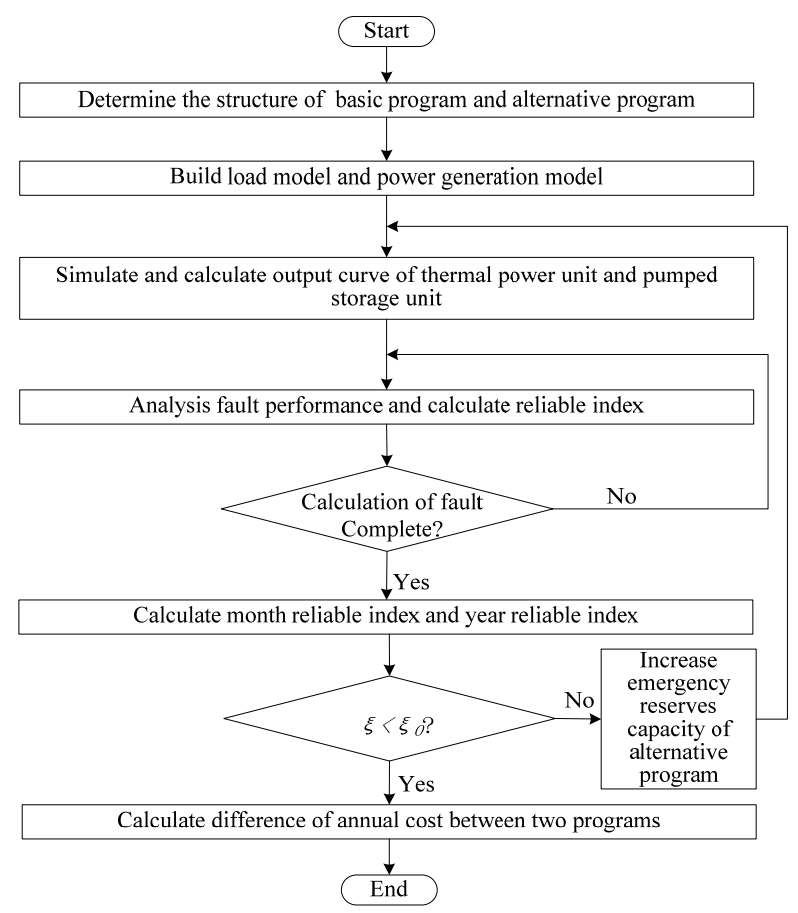

Figure 3. Flowchart of Frequency modulation benefit evaluation. remain capacity is put into pumping during low load period, and output in peak time is set be 75 percent of the pumping power in valley time [9].

In order to test the algorithm, summer and winter typical day of a provincial power grid in normal rainfall year day are selected to be the research subjects. Every planning scheme with different installed capacity is simulated detailed Based on the present status of power system, the main principles for the test is:

1) Basing on the installed capacity of every kind of power sets and the historical data of their output per year, the result of simulation for units except pumped storage units should be consistent with realities as far as possible.

2) The electric structure of this power grid is relatively complex, and all of the factors should be considered, including nuclear power, thermal power, hydropower, pneumoelectric and power from other areas.

3) The main power sources for peaking in the simulation are thermal power and pneumoelectric. In order to reduce wasted water for peak modulation, hydropower doesn't join peak-regulation in the summer and peakshaving depth in the winter is set to be $50 \%$. Moreover, nuclear power doesn't join peak-regulation all over the year.

4) The alternative power is thermal power when the pumped storage power station is removed from power system. All benefits are converted into standard coal equivalent.

The maximum load, minimum load and peak-vale difference are shown in Table 1. The load curves of summer typical day and winter typical day are given in Figure 4.

Table1. Load of two typical day load curves (MW).

\begin{tabular}{cccc}
\hline $\begin{array}{c}\text { Typical } \\
\text { day }\end{array}$ & $\begin{array}{c}\text { Maximum } \\
\text { Load }\end{array}$ & $\begin{array}{c}\text { Minimum } \\
\text { Load }\end{array}$ & $\begin{array}{c}\text { peak-vale } \\
\text { difference }\end{array}$ \\
\hline Summer & 87000 & 43514 & 43486 \\
Winter & 25800 & 14500 & 11300 \\
\hline
\end{tabular}

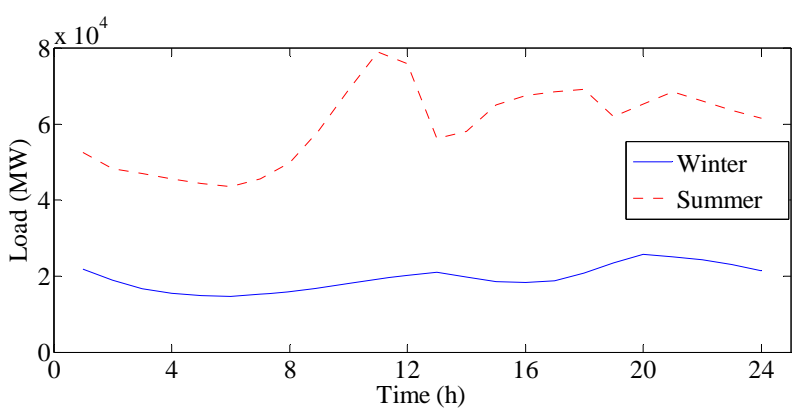

Figure 4. Load curves of summer typical day and winter typical day. 
The operation period of pumped storage power station is set to be 50 years. Investment of pumped storage unit is $3500 y u a n$ per capacity. The annual operation cost is 0.5 percent of investment expenses. Spinning reserve of system is 4.2 percent of maximum load [10]. One part of it is emergency reserve which is about 3 percent of maximum load and the remaining capacity is load reserve which is about 1.2 percent of maximum load. Prices of standard coal and nature gas are 900 yuan per ton, 3yuan per cubic meter, respectively.

Simulation results for different installed capacity of umped storage power station are shown in Table 2. The comparison of annual total cost, fuel cost, annual fixed running cost between alternative program and basic program is given in Figure 5. The results of this experiment lead to several conclusions:

1) There is a linear relationship between fixed running cost and installed capacity of pumped storage power station, as well as investment annual value and installed capacity of pumped storage power station. The variable running cost show little changes with the increase of installed capacity of pumped storage power station. So it can be ignored compared with fixed running cost and investment annual value.

Table 2. Simulation results for different installed capacity.

\begin{tabular}{|c|c|c|c|c|c|c|c|c|}
\hline $\begin{array}{l}\text { Installed } \\
\text { capacity }\end{array}$ & $\begin{array}{c}\text { Investment } \\
\text { annual value }\end{array}$ & $\begin{array}{c}\text { Fixed } \\
\text { running cost }\end{array}$ & $\begin{array}{c}\text { Variable } \\
\text { running cost }\end{array}$ & $\begin{array}{c}\text { Coal } \\
\text { consumption }\end{array}$ & $\begin{array}{l}\text { Load rate of } \\
\text { thermal plant }\end{array}$ & $\begin{array}{c}\text { Gas } \\
\text { consumption }\end{array}$ & $\begin{array}{l}\text { Annual } \\
\text { fuel costs }\end{array}$ & $\begin{array}{r}\text { Total } \\
\text { benefit }\end{array}$ \\
\hline MW & Million yuan & Million yuan & Million yuan & Million ton & -- & $\begin{array}{c}\text { Billion cubic } \\
\text { meter }\end{array}$ & Billion yuan & $\begin{array}{c}\text { Million } \\
\text { yuan }\end{array}$ \\
\hline 0 & 0 & 0 & 0 & 58.40 & $62.50 \%$ & 3.51 & 63.00 & 0 \\
\hline 4200 & 294 & 90.3 & 2.3 & 57.50 & $67.30 \%$ & 3.51 & 62.17 & 831 \\
\hline 4800 & 354 & 103.2 & 2.6 & 57.35 & $68.00 \%$ & 3.51 & 62.03 & 969 \\
\hline 5400 & 414 & 116.1 & 3 & 57.19 & $69.20 \%$ & 3.51 & 61.89 & 1117 \\
\hline 6000 & 474 & 129 & 3.3 & 57.02 & $70.50 \%$ & 3.51 & 61.72 & 1279 \\
\hline 6600 & 534 & 141.9 & 3.6 & 56.82 & $71.90 \%$ & 3.51 & 61.54 & 1464 \\
\hline 7200 & 594 & 154.8 & 3.9 & 56.66 & $74.30 \%$ & 3.51 & 61.40 & 1608 \\
\hline 8400 & 714 & 180.6 & 4.6 & 56.51 & $76.60 \%$ & 3.51 & 61.24 & 1763 \\
\hline 9000 & 774 & 193.5 & 4.9 & 56.42 & $77.60 \%$ & 3.51 & 61.18 & 1822 \\
\hline 9600 & 834 & 206.4 & 5.2 & 56.38 & $78.40 \%$ & 3.51 & 61.13 & 1875 \\
\hline 10200 & 894 & 219.3 & 5.6 & 56.33 & $79.20 \%$ & 3.51 & 61.08 & 1922 \\
\hline 10800 & 954 & 232.2 & 5.9 & 56.29 & $79.70 \%$ & 3.51 & 61.05 & 1958 \\
\hline 11400 & 1014 & 245.1 & 6.2 & 56.26 & $79.90 \%$ & 3.51 & 61.01 & 1994 \\
\hline 12000 & 1074 & 258 & 6.6 & 56.23 & $80.10 \%$ & 3.51 & 60.98 & 2023 \\
\hline 12600 & 1134 & 270.9 & 6.9 & 56.19 & $80.20 \%$ & 3.51 & 60.95 & 2051 \\
\hline 13200 & 1194 & 283.8 & 7.2 & 56.17 & $80.20 \%$ & 3.51 & 60.93 & 2075 \\
\hline
\end{tabular}

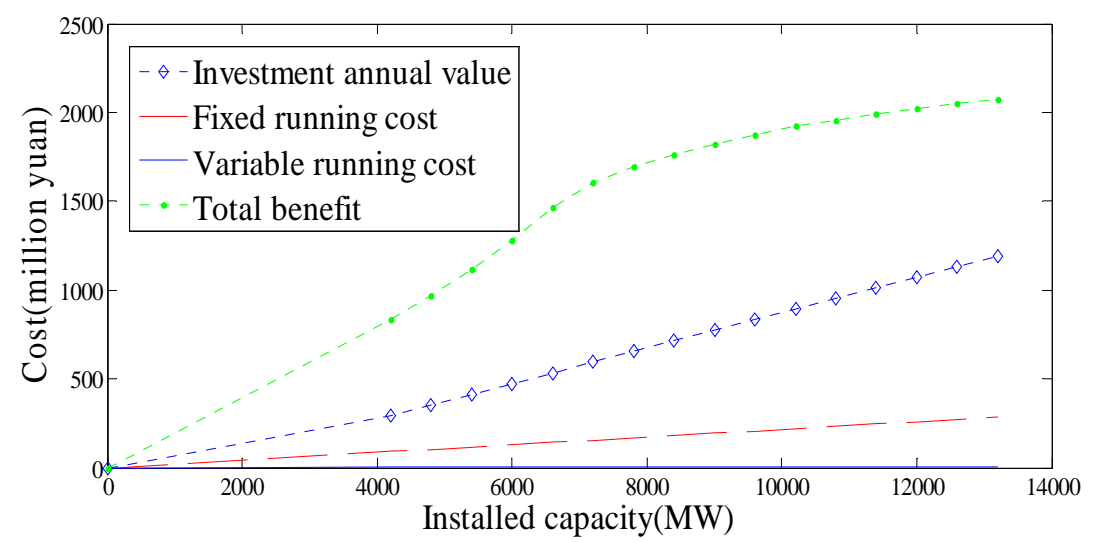

Figure 5. Cost comparison between alternative program and basic program. 
2) When installed capacity of pumped storage power station is less than $7200 \mathrm{MW}$, the benefits are obvious. The benefit will increase about 166.7 thousand tons of standard coal for every 600MW increase, about 150 million yuan when converted into economic benefit. The growth begins lower with the increase of installed capacity of pumped storage power station. When installed capacity is in the scope of $7200 \mathrm{MW}$ to $9600 \mathrm{MW}$, the benefit will increase about 88.9 thousand tons of standard coal for every $600 \mathrm{MW}$ increase, about 80 million yuan when converted into economic benefit. The benefit will be very low when the installed capacity continues to increase for there is only 24.4 thousand tons of standard coal increase for every $600 \mathrm{MW}$ increases, about 22 million yuan when converted into economic benefit.

3) When the growth of benefit is higher than that of annual running cost (less than $7200 \mathrm{MW}$ ), we can increase the installed capacity appropriately. And with the increase of installed capacity of pumped storage power station, growth of benefit slows significantly. Therefore, it can be concluded that the best installed capacity of pumped storage power station is $7200 \mathrm{MW}$.

\section{Conclusions}

The rapid development of economy exacerbates the power peaking contradiction. Power programming should adjust in time as the load changes. So how to determine the best installed capacity become more and more important to power system. This paper choose the day with maximum load as the typical day for every month and simulate the system running in two cases of whether the pumped storage power station is put into operation. Then build load model and power generation model to calculate the benefit of emergency use and frequency modulation, which are the major projects of dynamic benefits. The developed method employs the maximum benefit of the unit capacity as the objective function to get the best installed capacity of pumped storage power station by simulations. Tests on a provincial power grid have shown that the developed method has a meaningful guideline in practice.

\section{REFERENCES}

[1] H. L. Zhang, D. M. Xie, J. Y. Liu, et al., "Optimized Control of the Startup and Shutdown of Peaking Units," Journal of Engineering for Thermal Energy and Power, Vol. 20, No. 5, 2005, pp. 300-303.

[2] X. M. Yu, X. G. Xiong, Y. W. Wu, et al., "Discussion on Optimal Mode for Peaking Units Expansion Planning and Its Application,” Electric Power, Vol. 36, No.1, 2003, pp. 48-51.

[3] J. Barton and D. Infield, "Energy Storage and Its Use with Intermittent Renewable Energy,” IEEE Transaction. Energy Conversion, Vol. 19, No. 2, 2004, pp. 441-448. doi: 10.1109/TEC.2003.822305

[4] W. Leonhard and E. Grobe, "Sustainable Electrical Energy Supply with Wind and Pumped Storage: A Realistic long-term Strategy or Utopia,” Proceedings IEEE Power Engineering Society General Meeting, 2004, pp. 12211225.

[5] Anonymous, "Pumped-storage Project Updates," International Journal of Hydropower Dams, Vol. 9, No. 5, 2002, pp. 104-109.

[6] R. M. Burns and C. A. Gibson, "Optimization of Priority Lists for a Unit Commitment Program,” in Proceeding IEEE Power Engineering Society Summer Meeting, 1975.

[7] Narayana Prasad Padhy, "Unit Commitment-A Bibliographical Survey,” IEEE Transaction Power System, Vol. 19, No. 2, 2004, pp. 1196-1205. doi:10.1109/TPWRS.2003.821611

[8] H. K. Song, Y. D. Tang, G. Q. Tang, et al., “Analysis of Power Generation Enterprise Bidding Strategies Considering Demand Side Bidding," Electric Power Automation Equipment, Vol. 27, No. 6, 2007, pp. 47-50.

[9] K. Aoki, M. Itoh, K. Nara. and M. Kanezashi, “Optimal Long-term Unit Commitment In Large Scale Systems Including Fuel Constrained Thermal And Pumped Storage Hydro,” IEEE Transaction Power System, Vol. 4, No. 3, 1989, pp.1065-1073. doi:10.1109/59.32600

[10] K. Aoki, M. Itoh, T. Satoh, et al., “Optimal Long-term Unit Commitment in Large Scale Systems Including Fuel Constrained Thermal and Pumped-storage Hydro,” IEEE Transaction on Power Systems, Vol. 4, No. 3, 1989, pp. 1065-1073. doi:10.1109/59.32600 